\title{
Erratum to "Photostability studies on gemifloxacin and lomefloxacin in bulk powder and dosage forms" [Eur. J. Chem. 5 (1) (2014) 73-80]
}

\section{Marwa Hosny Tammam}

Drug Bioavailability Center, National Organization for Drug Control and Research (NODCAR), Giza, 35521, Egypt

*Corresponding author at: Drug Bioavailability Center, National Organization for Drug Control and Research (NODCAR), Giza, 35521, Egypt. Tel.: +2.011.12289346. Fax: +2.02.33379445. E-mail address: tammam.marwa@gmail.com (M.H. Tammam).

\section{ERRATUM INFORMATION}

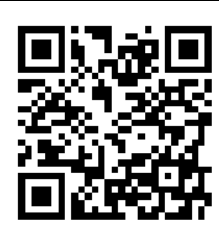

DOI: 10.5155 /eurjchem.5.4.695-696.1119

Received: 09 July 2014

Accepted: 13 July 2014

Online: 31 December 2014

\section{KEYWORDS}

HPLC

LC-MS/MS

Gemifloxacin

Lomefloxacin

Photostability

Fluoroquinolone drugs

\section{ERRATUM}

We recently published a paper entitled "Photostability studies on gemifloxacin and lomefloxacin in bulk powder and dosage forms" in Eur. J. Chem. 5 (1) (2014) 73-80 [1]. We provide the following errata for the above-mentioned paper.

The authors would like to replace forth sentence (on page 76, Section 3.2.) with "The mass spectra of GFLX solution after illumination exhibited a complete degradation of the drug solution and formation of four degradation products with molecular masses as follows: $335\left(\mathrm{M}-\Delta, \mathrm{CH}_{3}\right), 301\left(\mathrm{M}-\mathrm{F},-\Delta, \mathrm{CH}_{2} \mathrm{NH}_{2}\right), 294\left(\mathrm{M}-\mathrm{F}, \mathrm{COOH}, \mathrm{CH}_{3} \mathrm{O}\right)$ and $289\left(\mathrm{M}-\Delta, \mathrm{CH}_{3}, \mathrm{COOH}\right)$ for Degradation 1 (Deg. 1), Degradation 2 (Deg. 2), Degradation 3 (Deg. 3) and Degradation 4 (Deg. 4), respectively (Figure 7B)." due to the several typesetting mistakes.

The authors would like to replace Scheme 1 on page 76 with corrected Scheme 1 has been presented below: 


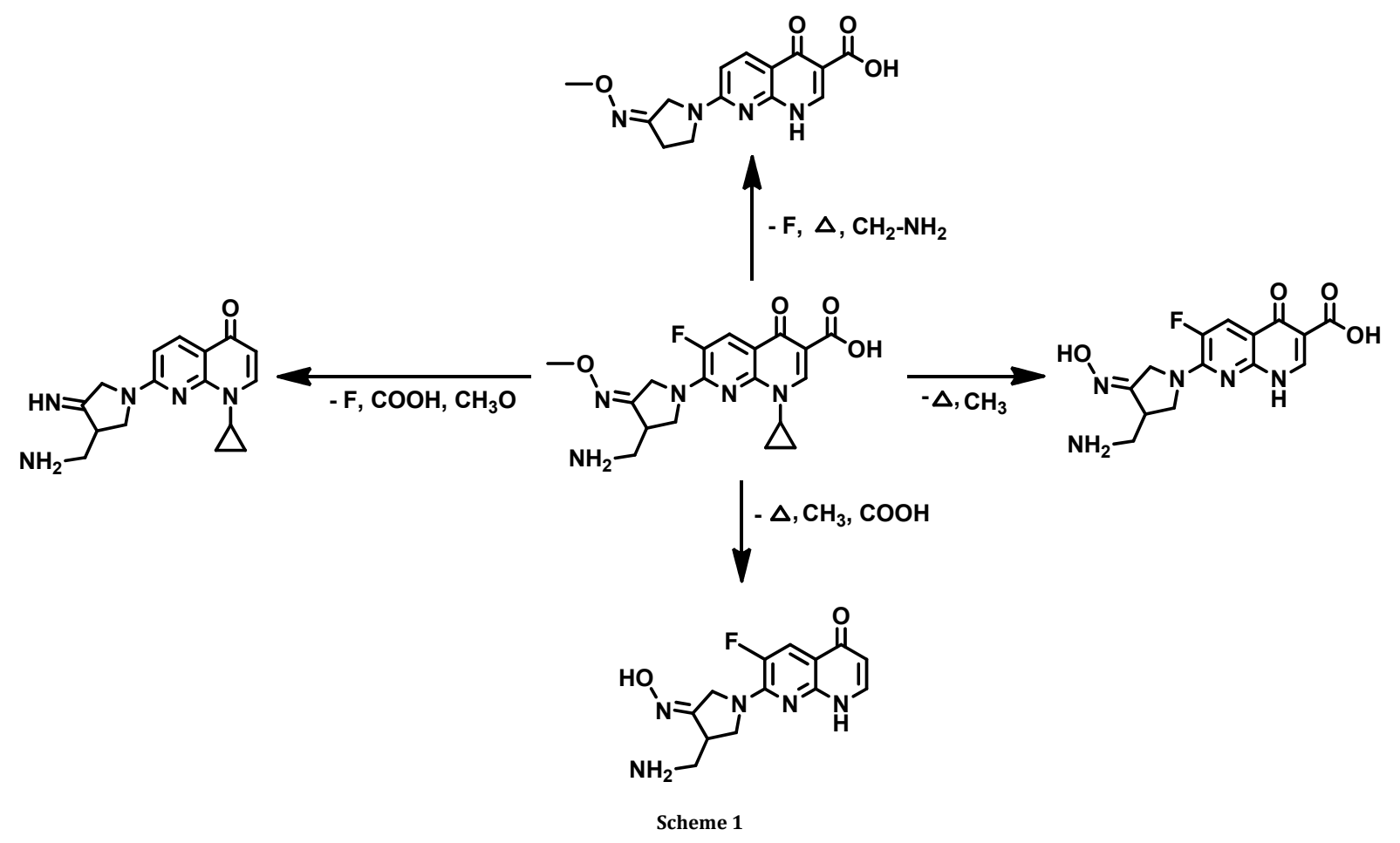

\section{References}

[1]. Tammam, M. H. Eur. J. Chem. 2014, 5(1), 73-80. 